MATEC Web of Conferences 10, 03001 (2014)

DOI: $10.1051 /$ matecconf/ 20141003001

(C) Owned by the authors, published by EDP Sciences, 2014

\title{
Relationship between Quality of Building Maintenance System and Occupant Satisfaction for Office Buildings
}

\author{
A.H.A Hamid, ${ }^{1,}$, M.H Othman ${ }^{2}$ \\ ${ }^{1,2}$ School of Housing, Building and Planning, Universiti Sains Malaysia, 11800, Penang, Malaysia
}

\begin{abstract}
Buildings will be weary, decaying and dirty as time goes by; but with highquality maintenance management we can prolong the life-span of building, provide building services and keep the building performance at its ultimate level. The importance of carrying out a systematic and routine maintenance is to conserve building performance. However, this task is often neglected due to various factors including misunderstanding the needs of the maintenance works and lack of budget allocation. This paper highlights the current practice of maintenance management that are being implemented in 6 office buildings located in Kuala Lumpur, Johor, Kedah and Pulau Pinang. Using the responses of questionnaire answered by 150 respondents employed from these selected offices, personal interviews and visual inspection the following findings were made: the occupants were satisfied with the maintenance management of their buildings elements and the delivery characteristics of maintenance works. Visual inspection however showed that some elements are not in a good condition. In conclusion, some recommendations are made to improve the existing system including the establishment of a maintenance plan, selection of experienced contractors and the provision of a service desk.
\end{abstract}

\section{Introduction}

All buildings need proper maintenance management hence the knowledge about building maintenance in this regard is very important especially during the diagnosing and building analysis works. In general, maintenance means to hold, keep, sustain or preserve the building or structure to an acceptable standard, in which acceptable standard is defined as one which sustains the utility and value of the facility. While maintenance management should properly be regarded as describing how a system of maintenance effort could be organized to deal with the problems of building maintenance as whole [1].

It will involve systematic approach in planning, organizing, monitoring and evaluating maintenance activities. This also means that financial considerations and techniques also play a vital role in enacted a good maintenance management. A good maintenance management is able to preserve an office building in its initial stage, as far as practicable so that it effectively serves its purpose. Systematic management and continuous maintenance works are necessary for mitigating the decaying process that will lead to unsafe condition [2].

\footnotetext{
${ }^{a}$ Corresponding author: hilcom@usm.my
} 
Some of the main purposes of maintenance works for the office buildings are to retaining value of investment of property and to presenting a good appearance. Therefore, this research aimed of the maintenance management system for office buildings which is the best practicable for the office buildings in giving an ultimate satisfaction to the occupants. Nowadays, people spend more time in their workplace. Due to this matter, this research chose the office building because satisfaction of the occupants within workplace environment is very important. One of the significance of maintenance management is it can affect occupants satisfaction on building performance where it can offer the occupants a positive environment which consequently will contribute to the productive and healthy life style [2].

For this study, the main aim was to evaluate the maintenance management in small office buildings. An office is generally a room or other area where people work, but may also denote a position within an organization with specific duties attached to it. Work spaces in an office are typically used for conventional office activities such as reading, writing and computer work. For this research, the type of work space chosen was team space.

In order to carry out this study, 6 small offices were selected. These offices were Selakta Indah Enterprise, Baling Bayu Engineering (M) Sdn Bhd, AMStrack Sdn Bhd, One Community Worldwide Sdn Bhd, Azizah Enterprise and SA Lee Architect Sdn Bhd. These offices are located in different states in Malaysia, covering the states of Kedah, Pulau Pinang, Kuala Lumpur and Johor. All these offices have meeting space and support spaces (such as filing space, storage space, print and copy area, pantry area, break area and etc.)

\section{Literature Review}

The term 'building' can be referred to one of the following: any human-made structure used or intended for supporting or sheltering any use or continuous occupancy or an 'act of construction' (i.e. the activity of building). One type of building is office buildings. For office building, it can be defined in many aspects as follows:

1. A building used for professional purposes, no part of which is used for living purpose [2]

2. A structure primarily used for the conduct of business such as administration, clerical services, and consultation with clients and associates. Such buildings can be large or small and may house one or more business concerns [3]

While building maintenance can be defined as that which is taken from the ground tends to return to the ground [4]. It seems true and legit; this statement of fact does explain why some form of maintenance is required to sum up the problem of deterioration and the care needed for its prevention. Building maintenance plays an important role in maintaining and keeping buildings in satisfactory condition. Neglecting the maintenance has accumulative results with rapidly increasing deterioration of the fabric and finishes of a building accompanies that will cause harmful effects on building contents and occupants.

Maintenance includes the costs of regular custodial care and repair, annual maintenance contracts, and salaries of facility staff performing maintenance tasks. Replacement items of minor value or having a life of less than five years are included as part of maintenance i.e. replacing light bulbs and repainting are normally included under the maintenance category [5]. In reality, maintenance works are not about given attention only but as well as having a budget allocated for maintenance works which seldom seem to be a prior consideration [6]. However, it is a fact that maintenance is the most important and the activity to be carried out to prolong or at least maintain serviceability of a structure until the end of its service life [7]

\section{Questionnaires Analysis}

There were 6 office buildings chosen for this research. All buildings are located within the Pulau Pinang, Kuala Lumpur, Kedah and Johor area. 


\subsection{Satisfaction level with maintenance management in the office on the implementation of maintenance works}

Table 1 shows the Mean Index (MI) for the questionnaire data analyses. For implementation work on external wall, internal wall, windows repair, electrical installation, door, air conditioning system, lighting system, fire fighting system and external building cleanliness, generally, the respondents totally agreed with the quality of maintenance management of these elements. The mean index (MI) was between 4.50 to 5.00 .

While for ceiling, sanitary, building structure, floor surface and internal building cleanse, toilet cleansing and finishing, the respondents were agreed to show their satisfaction level towards maintenance management of these element with the mean index value between 3.50 to 4.50 except for toilet cleansing element where the respondents satisfaction level is in neutral/undecided, with the mean index value between 2.50 to 3.50 .

Table 1. Data interpretation of understanding/ agreement based on respondents answers

\begin{tabular}{|c|c|}
\hline Indicator & Mean Index (MI) \\
\hline Totally Disagree & $0.00-1.49$ \\
\hline Disagree & $1.50-2.49$ \\
\hline Neutral/Undecided & $2.50-3.49$ \\
\hline Agree & $3.50-4.49$ \\
\hline Totally Agree & $4.50-5.00$ \\
\hline
\end{tabular}

\subsection{Satisfaction level with implementation of maintenance on delivery characteristics}

This section discusses the respondent's satisfaction level on delivery characteristics of services in their workplace. Based on the respondent's answers, delivery characteristics on information given on progress of repair work and time taken to complete repair work both are fell under neutral or undecided, while for standard workmanship, overall quality of services provided and general condition of building operation system was in the 'agree' status.

\subsection{Opinion on improving maintenance management in office building}

These are based on the occupants view on improving all elements i.e. office planning and scheduling, the types of planning and schedule used response on emergency defects. Overall, satisfaction of maintenance works and needed in hire professional maintenance manager in office fell under agree level, and the least number of mean index was 3.86 which was for the overall satisfaction of maintenance works.

\subsection{Visual Observation and Interview}

\subsubsection{Ceiling repair}

All the 5 offices have good quality of ceiling except Baling Bayu Engineering. Baling Bayu Engineering's ceiling was not in fine condition. All of the offices used the dropped ceiling type. Dropped ceiling is often a secondary ceiling; it is hung below the main (structural) ceiling. Based on interview done with Cik Hazwani from Baling Bayu, the ceiling is in bad shape condition because it is in an old building, approximately more than 40 years. According to her, so far no ceiling fell down although we can see from Figure 1 of the ceiling sheet is loose. 


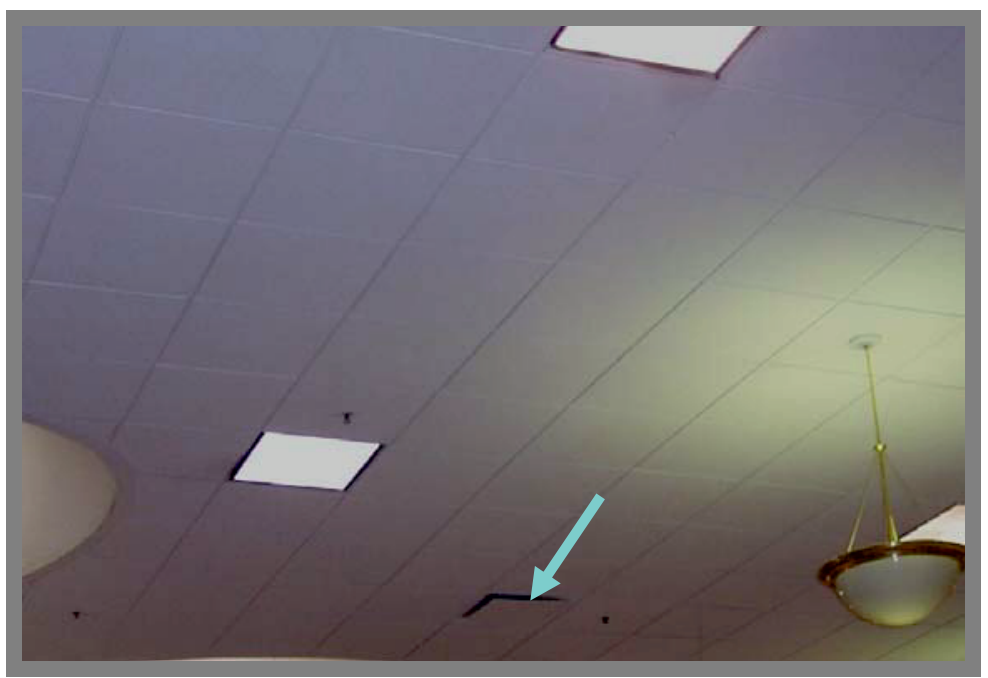

Figure 1. Ceiling in Baling Bayu Engineering shows the loose sheet of ceiling

\subsubsection{External building cleanliness}

During the visual inspection of one of the offices, it was found that the external cleanliness was in bad state (Figure 2). The stairs up to this office was smelly and had animal feces in a few places. Apart from that one office, there were no other offices that have bad external cleanliness. From the interview with each of offices representative, the cleanliness of the externals of the buildings is handled by cleaners from the Majlis Daerah (local council) since all the offices are located in the respective Majlis Daerah buildings.

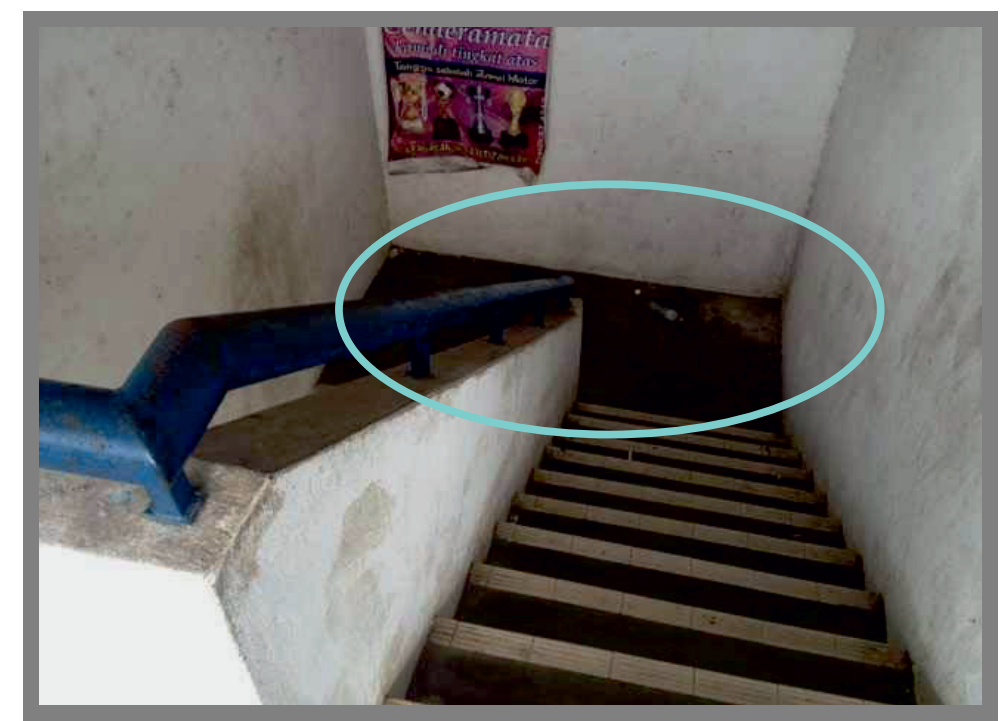

Figure 2. External cleanliness at one of the offices - animal faeces on the floor

\subsubsection{Toilet cleansing}

All the offices have clean toilets except one where the toilet floor had not been clean regularly where the floors was mouldy and that can be dangerous to the occupants. 


\subsubsection{Floor surface repair}

From the observations, all offices have good maintenance on floor surface repair. There were no broken or spalling concrete. Most of offices used carpet to avoid floor damage and for comfort purposes. There were no unevenness or floor bulging that can make trip the occupants.

\subsubsection{Door \& Window repair}

Doors and windows were in good conditions for all offices except for one office. The type of door used in that office is the sliding door and unfortunately, the door had been broken and cannot slide smoothly and often gets stuck. According to the officer concerned, they have called technicians to repair the door but the problem keeps recurring. The problem recurs probably because of the age of the door and the way occupants handle the door.

\subsubsection{Electrical installation, air conditioning system, firefighting system}

Based on observations, all electrical installation were working very well. This included the air conditioning system and fire fighting system. For electrical installation, all socket and plug are in good condition, where there is no broken socket or plug. Besides, all the office representatives agreed that their offices did not have any blackouts caused by over usage. For the air conditioning system, all offices have set their air conditioning system temperature in the range of $22-28 \mathrm{oC}$.

This temperature according to them is favourable temperature and comfortable for them to do work because nowadays the external temperature is quite high. While for the firefighting system, all signage's has been located in correct places, for example, the emergency way signage's are located at stairs and on top of door frames. The hoses and sprinklers have also been located and installed to prevent fire from spread or at least to control the fire before fire-fighter arrives.

\section{Conclusion and Recommendations}

This paper summarizes the findings of a basic study on the level of maintenance management system undertaken for selected office buildings in Kedah, Johor, Pulau Pinang and Kuala Lumpur as well as to evaluate the quality of services in those offices. The case study result indicated that maintenance approach undertaken for offices building in Malaysia still needs further improvements. Based on the questionnaire survey, most of the respondents are satisfied with the state of maintenance of their offices. It was found that the major issues contributing to the lack of a proper maintenance program in office building are as follows:

i) There is an absence of the professional maintenance management in offices especially in small offices such as scheduling or planned inspection concerning the services systems, building fabrics or the structural or non-structural elements. Most of the offices administration preferred to outsource the maintenance work or repairing works to external contractors.

ii) With the lack of budget allocated for maintenance work, offices administrators prefer to do corrective maintenance approach rather than preventive maintenance. Based on the interviews conducted with the office representatives, the budget allocated for repairing and maintenance works are not sufficient and is very limited.

From the survey, we can conclude that most occupants in the selected case studies are satisfied with their maintenance management on buildings elements and are also satisfied with the delivery characteristics of the maintenance works. However, visual inspection on some of elements shows that they are not really in a good condition. In order to improve maintenance management, the following recommendations are suggested:

1. Prepare a guideline and established maintenance plan as a standard guideline in building that will assist the maintenance schedule and planning 
2. When doing maintenance works or repair is in progress, contractors should provide information regarding the defects to the building users so that they can gain some knowledge regarding maintenance works, the significance of maintenance and how to prolong the life of services, fabrics and building performance in the correct manner of using facilities [8]. Building users should be encouraged to report quickly whenever they detect defects in building elements.

3. Develop a service desk where it is easier and the fastest way for occupants to report and complain any dissatisfaction towards building defects or non-functioning elements of the services [9].

4. Selection of external contractors should base on expertise. Repair and maintenance work by general contractor may not adhere to the required standard due to lack of expertise and experience which will cause building devaluation.

\section{References}

1. B. Hamilton, M. Wan Salleh, Maintenance of Building Important, 2001, pp: 22-27

2. E.B. Feldman, Building Design for Maintainability, New York: McGraw-Hill, 1975, pp: 56-64

3. P. Barrett, Development of a Post Occupancy Building Appraisal Model, Facilities Management: Research Directions, RICS Books, 1992, pp: 1-13

4. P.D. Leedy, J.E. Ormond, Practical Research: Planning and design, 7th ed. Ohio: Merrill Prentice Hall, 2001, pp: 32-37

5. E.D. Mills, Building Maintenance and Preservation: a guide for design and Management, 2nd ed. Oxford: Butterworth-Heinemann, 1994, pp: 67-81

6. R.B.H. Ahmad, Maintenance Management and Services (Case Study: PERKESO, Buildings in Peninsular of Malaysia), Unpublished Master's Thesis, University Technology Malaysia, 2006

7. S. Melvin, Designing for Maintenance, Nelson Mandela, Metropolitan Universiti, 2006

8. A.H. Mohammed, W.M. Wan Mat, Teknologi Penyelenggaraan Bangunan, Kuala Lumpur: Dewan Bahasa dan Pustaka, 2009, pp: 33-37

9. M.Y. Hamid, S. Ngah Abdul Wahab, Teori dan Praktis Pemeriksaan Bangunan, Penerbit Press Universiti Teknologi Mara, 2012 